\title{
DISERTACIONES
}

ESTUDIOS

\section{TRES CASOS DE PERIODISMO NARRATIVO EN MÉXICO IMPULSADOS POR LA CRISIS DE LAS INSTITUCIONES GUBERNAMENTALES}

\author{
Three Cases of Narrative Journalism in Mexico Promoted by the Crisis of \\ Governmental Institutions
}

\section{Três casos de jornalismo narrativo no México impulsionado pela crise das instituições governamentais}

Rafael Gerardo Vargas Pasaye, Universidad Iberoamericana León (México) rafaelvargaspasaye@gmail.com

\section{Recibido: 25 de noviembre de 2019}

Aceptado: 8 de mayo de 2020

Fecha de prepublicación: 15 de octubre de 2020

\section{RESUMEN}

La sociedad en México ha perdido parte de la credibilidad y la confianza de algunas instituciones gubernamentales en buena medida porque estas no dan respuesta a sus necesidades, y se ven rebasadas en ámbitos relacionados con corrupción, procuración de justicia y seguridad. En esos espacios, el periodismo narrativo actual ha descrito las injusticias y consecuencias de la crisis que representa dicho debilitamiento. Este texto analiza tres piezas que, por su oportunidad, relevancia y reconocimiento público, lo ejemplifican: El cártel de Sinaloa de Diego Enrique Osorno (2009), La fosa de agua de Lydiette Carrión (2017) y La estafa maestra de Nayeli Roldán, Miriam Castillo y Manuel Ureste (2018). Selección que responde a la relevancia y el reconocimiento público, ya que, además de oportunos, llegaron a convertirse incluso en un parámetro comparativo que forma parte del lenguaje cotidiano. 


\title{
DISERTACIONES
}

ESTUDIOS

Los desafios del periodismo narrativo

ISSN: 1856-9536

Doi: https://doi.org/10.12804/revistas.urosario.edu.co/disertaciones/a.8474

Volumen 14, Número 1 / Enero-junio 2021

Versión PDF para imprimir desde

http://revistas.urosario.edu.co/index.php/disertaciones

Se recurre al método hermenéutico bajo la lógica de su forma de trabajo: interpretación del texto, consideración del contexto y conclusión, para lo cual se concluye con una generación de categorías para los tres casos: elementos de denuncia, pruebas, testimonios, seguimiento y metáforas, por lo que se pueden analizar como un conjunto de piezas perteneciente a un contexto mexicano. Se concluye que el debilitamiento de las instituciones en México con índices de calificación más bajos por abuso de autoridad, ausencia de resultados y exceso de corrupción, por ejemplo, incrementaron un vacío de poder que detonó parte del periodismo narrativo que ahora se observa, y que también refleja las consecuencias de esa crisis.

Palabras clave: periodismo narrativo; crisis; crónica; credibilidad.

\begin{abstract}
Mexico has lost part of the credibility and trust in some government institutions because they do not respond to their needs, and are overwhelmed with areas related to corruption, justice and security. In those cases narrative journalism has described the injustices and consequences of the crisis that represent that weakness. This text analyzes three pieces that exemplify it: El cartel de Sinaloa by Diego Enrique Osorno (2009), La fosa de agua by Lydiette Carrión (2017), and La estafa maestra by Nayeli Roldán, Miriam Castillo and Manuel Ureste (2018). These selections respond to the relevance and public recognition, because in addition to timely, they have turned to a comparative parameter that has become part of the everyday language. The hermeneutical method is used to it's logic form: interpretation of the text, consideration of the context and conclusion, which it concludes with a generation of categories for the three cases: elements of complaint, evidence, testimonies, follow-up and metaphors, so they can be analyzed as a set of pieces belonging to a Mexican context. It is concluded that the weakening of institutions in Mexico with lower rating indices due to abuse of authority, lack of results and excess corruption, for example, the increased of a power void that triggered part of the narrative journalism, and which also reflects the consequences of that crisis.
\end{abstract}

Keywords: Narrative journalism; crisis; chronicle; credibility.

\section{RESUMO}

A sociedade mexicana perdeu parte da credibilidade e da confiança de algumas instituições governamentais, principalmente porque não atendem às suas necessidades e estão sobrecarregadas em áreas relacionadas à corrupção, aplicação da lei e segurança. Nesses espaços, o jornalismo narrativo atual tem descrito as injustiças e consequências da crise que esse enfraquecimento representa. Este texto analisa três peças que a exemplificam pela oportunidade, relevância e reconhecimento público: El cartel de Sinaloa, de Diego Enrique Osorno (2009), La fosa de agua, de Lydiette Carrión (2017) e La scam maestra, de Nayeli Roldán, Miriam Castillo e Manuel Ureste (2018). Seleção que responde à relevância e ao reconhecimento público, pois, além de oportuna, tornou-se até um parâmetro comparativo que faz parte da linguagem cotidiana. O método hermenêutico é utilizado segundo a lógica da sua forma de trabalho: interpretação do texto, consideração do contexto e conclusão, para o que se conclui com uma geração de categorias para 
os três casos: elementos de reclamação, provas, testemunhos, seguimento e metáforas, para que possam ser analisadas como um conjunto de peças pertencentes a um contexto mexicano. Conclui-se que o enfraquecimento das instituições no México com índices de avaliação mais baixos por abuso de autoridade, falta de resultados e excesso de corrupção, por exemplo, aumentou um vácuo de poder que detonou parte do jornalismo narrativo que agora se observa, e que também reflete as consequências dessa crise.

Palavras-chave: jornalismo narrativo; crise; crônica; credibilidade.

Este texto responde a la inquietud de hacia dónde se dirige el periodismo narrativo en México y plantea que es en dirección a reflejar acontecimientos que ha dejado de atender el gobierno, con tres casos donde el común denominador es la ausencia de autoridad institucional.

El periodismo narrativo refleja un momento de un contexto dado, en este caso uno de violencia, abuso y falta de ejecución de las labores para las cuales fueron creadas, plasmados primero en medios de comunicación y después en formato de libro, cuya relevancia los llevó a obtener premios, reconocimiento público, y además tuvieron repercusión en ámbitos legales posterior a su publicación.

\section{Antecedentes}

Las instituciones gubernamentales en México han sufrido un desgaste en credibilidad acompañado de bajas calificaciones en años recientes. La relación de poder entre la sociedad misma y la clase gobernante se ha modificado, su estructura de prácticas recurrentes (Giddens, 1999) ha devenido en que, llegado el momento de evaluar el ciudadano a sus instituciones, castigue con números bajos.

Empresas como Consulta Mitofsky desde hace años han realizado ejercicios estadísticos que dan una idea de la percepción que tiene la sociedad de algunas instituciones. En el estudio "México: confianza en instituciones 2019" (2019), podemos observar que en una escala del 1 al 10, donde el 1 es la más baja y el 10 la más alta calificación, las instituciones con mejores resultados fueron universidades con 7,3, Ejército con 7,0 y Presidencia con 7,0. Es de subrayar esta calificación en el registro de Presidencia al dar un salto notorio, ya que sus resultados en años anteriores habían sido muy bajos: 5,1 en octubre de 2018, 4,8 en octubre de 2017, 5,1 en octubre de 2016 y 5,7 en septiembre de 2015 (Mitofsky, 2015, 2016, 2017, 2018). 


\section{DISERTACIONES}

ESTUDIOS

Los desafios del periodismo narrativo

ISSN: 1856-9536

Doi: https://doi.org/10.12804/revistas.urosario.edu.co/disertaciones/a.8474

Volumen 14, Número 1 / Enero-junio 2021

Versión PDF para imprimir desde

http://revistas.urosario.edu.co/index.php/disertaciones

Estos datos reflejan que algunas instituciones de gobierno han venido perdiendo credibilidad y confianza con la sociedad; influyen también otros factores, como lo competido y cerrado de los resultados electorales: la elección presidencial en México de 2006 terminó con una diferencia entre el primer y segundo lugar del 0,56 \% de votos, donde se juega un papel interesante al momento de tratar de que la sociedad apoye un proyecto por el que no necesariamente votó (Nacif, 2007).

También se relaciona con la ausencia de resultados de parte de la clase gobernante, las diversas promesas de campaña al momento de llegar a ser gobierno y no cumplirse en su totalidad generan que los problemas se expandan y lleguen hasta áreas estratégicas para gobernar: la seguridad y la procuración de justicia, donde probablemente se ha dado el mayor desgaste en la credibilidad y confianza de la sociedad mexicana con sus instituciones (Rosen \& Zepeda, 2015).

Esta coyuntura ha puesto al descubierto algunos casos que han catapultado ese enojo social contra la injusticia que se ha presentado en ciertas instituciones (Basañez, 1990), y es allí donde el periodismo narrativo contemporáneo en México ha hilvanado algunas de las historias que se analizan.

La crisis de las instituciones la entenderemos de inicio cuando pierden su poder político (Deutsch, 1969), misma que también se refleja en el periodismo actual, el cual se enfrenta a una dinámica con características del modelo político-económico (Toussaint Alcaraz \& García Méndez, 2017) y a la inmediatez por ganar la primicia, con las diversas características y formas como la sociedad se entera hoy de las noticias y, por lo tanto, los nuevos canales a través de los que se comunica o transmite la información (García Jiménez et al., 2018; Amado, 2016).

Sin embargo, en México en los últimos años una crisis particular ha impulsado un periodismo narrativo (Sims, 1996) de descripción y denuncia, que refleja los hechos que se suscitan cuando esa crisis deja vacíos de gobernabilidad e institucionalidad, como lo son la violencia, la presencia de los carteles de la droga y los actos de corrupción perpetuados desde dentro del gobierno.

Este periodismo narra las consecuencias de la crisis institucional (Novak, 2018) y lo hacen periodistas que no buscan tanto los reflectores como los cronistas de antaño, como señala Abreu: "En los años sesenta, la crónica se había vuelto en México una necesidad de expresión directa y comprometida de la realidad política, social y cultural, el cronista era el encargado de recoger elementos de la vida y presentarlos en una forma nueva, en la que el lenguaje podía operar un cambio en los hábitos de la prensa" (2007, p. 21).

El periodismo narrativo que se menciona conlleva características del periodismo literario (López, 2010; Hartsock, 2000) y parte de la crisis que se genera al dejar de cumplirse las funciones en la administración pública.

La capacidad de influencia en el cambio social y político de los acontecimientos narrados en las piezas periodísticas dan muestra de que el problema es mucho mayor de lo que abarca la denuncia; el trabajo expuesto en los tres casos ha ayudado a poner bajo la lupa los territorios de conflicto, que van desde la lucha contra la impunidad hasta la justicia en el ámbito legal.

\section{Metodología}

Este análisis contiene tres ejemplos significativos del periodismo narrativo reciente en México impulsado por la crisis institucional en su gobierno, en particular la que tiene que ver con impartición de justicia, corrupción y seguridad: La fosa de agua de Lydiette Carrión (2017), La estafa maestra de Nayeli Roldán, Miriam Castillo y Manuel 


\section{DISERTACIONES}

Ureste (2018), pertenecientes al equipo de la plataforma web Animal Político; y El cártel de Sinaloa de Diego Enrique Osorno (2009).

Se recurre al método hermenéutico bajo la lógica de su forma de trabajo: interpretación del texto, consideración del contexto y conclusión (Vargas, 2007), para lo cual se concluye con una generación de categorías para los tres casos.

La selección que se hace de los materiales responde a la relevancia y el reconocimiento público, ya que, además de oportunos, cada uno tuvo posicionamiento y se reflejó en las ventas que representó para las editoriales. También por un parámetro comparativo, pues empezaron a formar parte del lenguaje cotidiano, sobre todo con otros hechos (González, 2019).

Así como en la visibilidad que se les dio a los temas tratados en el momento que sucedieron los hechos (Bautista Farías, 2018), además de los reconocimientos que les fueron otorgados (incluyendo el Premio Ortega y Gasset de Periodismo 2018 en el caso de La estafa maestra, o presentaciones en la Cámara de Diputados de La fosa de agua), las investigaciones académicas que han suscitado (Pastor, 2017; Mercado, 2016; Sandoval, 2020) y las repercusiones legales con algunos personajes que se mencionan en sus investigaciones que se dieron desde su publicación.

Las obras se analizaron partiendo de los hechos que reflejan un debilitamiento del gobierno y, por ende, de las instituciones que representaban y considerando su mecánica de trabajo, siendo este la del periodismo narrativo actual. El objetivo es analizar las piezas recientes del periodismo narrativo mexicano que ha enfocado su interés en vacíos generados por el no cumplimiento de las instituciones.

El proceso de investigación comprendió la lectura interpretativa de cada obra, se hallaron los puntos en común que tienen para formar parte de una misma generación de periodismo narrativo en México impulsado por el debilitamiento en las instituciones y se llegó a las conclusiones.

En México, como en buena parte de Latinoamérica, el periodismo narrativo goza de cabal salud (Nadeau, 1999; Cairati, 2013), y en épocas recientes se ha dado sobre todo en las revistas, tanto en papel como en su versión digital (Puerta Molina, 2019), por lo que este trabajo solo toma una muestra muy pequeña pero representativa del acontecer contemporáneo.

\section{Resultados}

El periodismo narrativo actual en México ha encontrado una veta en la denuncia y exposición de temas que han generado las crisis y el debilitamiento de instituciones de gobierno, como lo son la corrupción, la ausencia de justicia y la carencia de resultados en la estrategia para enfrentar el problema de la violencia, en particular contra el narcotráfico.

En esos espacios de vacío de la tarea institucional, la sociedad ha manifestado su rechazo y lo ha denunciado, en particular en la labor en la procuración de justicia. De igual forma, gracias a la búsqueda de información se ha logrado llegar a entramados de las mismas instituciones de gobierno que han tenido consecuencias legales, como llevar a prisión a figuras de la vida política.

El periodismo narrativo ha ayudado a entender el fenómeno de la violencia en México en el caso particular de la descripción de uno de los grupos de mayor proyección, como lo es un cartel del llamado narcotráfico. 


\section{DISERTACIONES}

ESTUDIOS

Los desafios del periodismo narrativo

ISSN: 1856-9536

Doi: https://doi.org/10.12804/revistas.urosario.edu.co/disertaciones/a.8474

Volumen 14, Número 1 / Enero-junio 2021

Versión PDF para imprimir desde

http://revistas.urosario.edu.co/index.php/disertaciones

Después del análisis de La fosa de agua de Lydiette Carrión (2017), La estafa maestra de Nayeli Roldán, Miriam Castillo y Manuel Ureste (2018), y El cártel de Sinaloa de Diego Enrique Osorno (2009) se encontraron puntos en común entre ellos para justificar su selección y sustentar que, a partir del vacío que están dejando ciertas instituciones del gobierno mexicano, el periodismo narrativo ha encontrado una vertiente para su desarrollo que contempla los elementos que se exponen en la tabla 1.

Tabla 1. Relaciones

\begin{tabular}{l|c|c|c|c|c}
\multicolumn{1}{c|}{ Obra/elementos } & Denuncia & Pruebas & Testimonios & Metáforas & Seguimiento \\
La fosa de agua & Sí & Sí & Sí & Sí & Sí \\
\hline La estafa maestra & Sí & Sí & Sí & No & Sí \\
\hline El cártel de Sinaloa & Sí & Sí & Sí & Sí & Sí \\
\hline
\end{tabular}

Fuente: elaboración propia.

Luego de analizar los textos, se suma el hecho del contexto en el que fueron publicados, punto que se abunda en el análisis de cada uno. Los resultados arrojan que los tres recurren a la exposición o denuncia como hilo conductor; los tres presentan pruebas y testimonios; por la naturaleza de los trabajos, en ellos recae el peso de la credibilidad y de la tarea que deja de cumplir el Estado.

Por último, solo La estafa maestra (2018) queda al margen en el uso de metáforas y se ciñe más a los datos que recopila, mientras que La fosa de agua (2017) y El cártel de Sinaloa (2009) sí recurren al uso de la metáfora. Además, las tres tuvieron seguimiento en los actos señalados, ya fuera visibilizando el tema, generando las denuncias penales correspondientes, cambiando a los responsables de áreas definitorias en los procesos, por citar los más visibles.

\section{Discusión}

En México, la crónica ha sido un género bien labrado que se puede consultar en compilaciones como $A$ ustedes les consta (Monsiváis, 1980) o El fin de la nostalgia (Valverde \& Argüelles, 1992), y en figuras emblemáticas como Ángel de Campo, quien firmó la mayoría de sus trabajos como Micrós y Tick-Tack, José Alvarado, Jorge Ibargüengoitia, Ricardo Garibay, Vicente Leñero, Germán Dehesa, José Joaquín Blanco, Sergio González Rodríguez, Ignacio Trejo Fuentes y Emiliano Pérez Cruz.

El cronista, a decir de Monsiváis, refleja un episodio de la cotidianidad, donde por supuesto cabe la denuncia, a final de cuentas se trata de ser el testigo fiel de la historia. "Si el poeta es el maestro de la Nación, el cronista es su memoria y en la crónica opone la realidad de las costumbres a la irrealidad de las pretensiones 'cosmopolitas', erigiendo un género ambiguo que va del anticolonialismo al chovinismo y de regreso" (Monsiváis, 1980, p. 25).

Las crónicas son una pista, el santo y seña de un comportamiento social, es un momento, una fotografía del instante, allí se pueden tener la hebra de los otros detalles que otros géneros periodísticos (Cantavella \& Serrano, 2004) como las noticias o las entrevistas tal vez no logren captar, los olores, humores, colores, de un instante. 


\section{DISERTACIONES}

ESTUDIOS

Los desafíos del periodismo narrativo

ISSN: 1856-9536

Doi: https://doi.org/10.12804/revistas.urosario.edu.co/disertaciones/a.8474

Volumen 14, Número 1 / Enero-junio 2021

Versión PDF para imprimir desde

http://revistas.urosario.edu.co/index.php/disertaciones

En el prólogo del libro El fin de la nostalgia, Carlos Monsiváis se pregunta ¿cuál es el papel de la crónica? y responde: "En lo tocante a su dimensión moral, una idea que arraiga (y ya requerida de matices): tarea urgente de la crónica es darle la voz a los que -en el espacio público- no la tienen” (Valderde, 1992, p. 23).

Es allí donde la crónica y el actual periodismo narrativo toman un aire impulsado por la crisis de las instituciones de gobierno en México. Este tipo de crisis exige un periodismo narrativo que esté a la altura de las mismas realidades complejas que necesitan ser explicadas (Sabaté et al., 2019), y es así como en épocas recientes se cuenta en México con obras que conllevan la denuncia como bandera.

Se habla de un periodismo narrativo pensado, como lo diría Joshua Benton (Sabaté et al., 2019), disruptivo desde su nacimiento. Pareciera ser, como indica Claudia Darrigrandi (2013), "que la función social y el activismo político de los periodistas narrativos trascienden el traspaso de información”. Es una realidad que el inicio del siglo xxı trajo también una nueva manera de reflejar los hechos, pasa de la crónica al periodismo narrativo, entendido como lo hace ver Leila Guerriero en una entrevista: "Básicamente es la convicción de que las historias deben ser narradas, que no da lo mismo contar la historia de cualquier manera. La forma de un texto, el uso del lenguaje, el ritmo, el clima son tan importantes como la historia que se va a contar" (Villarreal, 2012).

Bajo este contexto es que el periodismo narrativo en México ha sido impulsado por la crisis de las instituciones de gobierno en años recientes, sobresaliendo tres: la que tiene que ver con una crisis de corrupción plasmada con La estafa maestra (2018) por el equipo de Animal Político, de vacío de poder con El cártel de Sinaloa (2009) de Diego Enrique Osorno y de las instituciones que parecen no hacer su trabajo llevado a La fosa de agua (2017) de Lydiette Carrión.

\section{Tres casos impulsados por la crisis}

El desgaste de las instituciones, entendidas como las que se van consolidando con el tiempo (Giddens, 1999), ha tenido sus consecuencias en las bajas calificaciones que le otorga la sociedad, así como en la credibilidad y confianza que han venido perdiendo con el paso de los años.

El tema del narcotráfico deviene de décadas atrás, y el libro El cártel de Sinaloa (Osorno, 2009) no es el primero en tocar el tema, pero sí marcó un momento de ruptura con lo que se venía presentando en esa época, que es cuando el entonces presidente Felipe Calderón anuncia su lucha contra el narcotráfico, había, por lo tanto, que explicarle a la gente cómo era uno de los grupos delincuenciales de mayor peso en México y el extranjero.

Casi una década después salieron a la luz dos piezas en formato de libro que ya habían tenido sus adelantos en medios de comunicación impresos y digitales. Por un lado, La estafa maestra (Roldán et al., 2018), investigación que describió con lujo de detalle el método que se siguió desde dependencias del gobierno mexicano, en este caso la Secretaría de Desarrollo Social, encargada sobre todo de los programas sociales, y su triangulación de fuertes cantidades de dinero a través de instituciones de educación superior para llegar a empresas que o no existían o a los pocos días desparecían. El enojo social fue mayor precisamente por involucrar a una de las instituciones mejor calificadas por la misma sociedad: la universidad.

La otra pieza es La fosa de agua (Carrión, 2017), una compilación de diez historias de denuncias que dibuja de cuerpo entero el cáncer que se vive en los procesos de desaparición de mujeres, y los laberintos por los que tienen que pasar los familiares para dar seguimiento a los casos y descubrir, a veces por investigaciones propias, 


\section{DISERTACIONES}

ESTUDIOS

Los desafios del periodismo narrativo

ISSN: 1856-9536

Doi: https://doi.org/10.12804/revistas.urosario.edu.co/disertaciones/a.8474

Volumen 14, Número 1 / Enero-junio 2021

Versión PDF para imprimir desde

http://revistas.urosario.edu.co/index.php/disertaciones

que fueron asesinadas y sus cuerpos arrojados en un canal de agua sucia conocido como río de los Remedios en la frontera entre la Ciudad de México, capital del país, y el Estado de México. Una estela de feminicidios que deja la crisis en la procuración de justicia.

En cada uno de ellos se guía con el compromiso con la información (Puerta Molina, 2018), así como también con una prosa que se enriquece de los diversos géneros para conformar un periodismo narrativo completo. Además de darle la razón a uno de los periodistas más reconocidos: "El verdadero periodismo es intencional, a saber: aquel que fija un objetivo y que intenta provocar algún tipo de cambio" (Kapuscinski, 2002, p. 38).

\section{La fosa de agua}

Blanche Petrich escribió en el prólogo del libro La fosa de agua (2017):

Lo que sale a la luz son las miserias de un aparato judicial plagado de policías que de día patrullan y de noche delinquen, de Ministerios Públicos que dormitan sobre los expedientes, de fiscales que persiguen la máxima regla del menor esfuerzo y se detienen ahí donde creen que pueden 'pisar callos', ya sea por conveniencia política o por complicidades inconfesables. Es el fracaso de las instituciones responsables de proteger a la población, a las niñas, a sus familias y de hacerles justicia.

Es el preámbulo de los testimonios que va plasmando Lydiette Carrión (2017). En las páginas de esta obra utiliza la entrevista, así como la recopilación de datos, y va con largo aliento puntualizando, llega a lo profundo de las mismas investigaciones, desvela la crisis de las instituciones que deberían velar por la seguridad y la impartición de justicia de los ciudadanos.

Habla de los otros personajes que también participan en el ciclo de procuración de justicia: el abogado, el agente de ministerio público, el policía, el vecino, el testigo, la autoridad y su contraparte: la ausencia.

En la pluma de la periodista, los feminicidios cobran un tinte distinto, los nombres de las mujeres que perdieron la vida en muchos de sus trámites no corrieron con la suerte del trato digno, es por eso que parece un homenaje mínimo la recuperación de sus casos con estos testimonios. A la par da cuenta de las investigaciones paralelas que hicieron los mismos familiares, las pesquisas que tenían que hacer con sus propios recursos para no perder la esperanza.

En sus palabras lo dice así la autora: "Aunque es real que cuando una persona desparece es necesario buscar pistas en el entorno cercano, los judiciales mexicanos han desarrollado la facultad de hacer sentir culpables a los familiares de las víctimas; de hacerles sentir miedo al denunciar" (Carrión, 2017, p. 45).

Y antes de cerrar su obra pregunta: "México está sumido en la desmemoria. ¿Seremos capaces de hallar lo que necesitamos recordar?” (Carrión, 2017, p. 227). Un caso que se impulsa en la crisis de las instituciones que no hacen su trabajo como se supone deberían hacerlo.

En el contexto mexicano, los feminicidios han ido en aumento año con año, 604 en 2016, 741 en 2017, 891 en 2018, 983 en 2019 y hasta el 31 de marzo de 2020 se contabilizaban 240 casos (SESNSP, 2020a).

Con los testimonios de esta obra se pone al descubierto el debilitamiento institucional en sus diversos espacios: desde el ministerio público, los agentes de guardar el orden, las autoridades competentes.

Después de la publicación del libro compuesto por diez casos, algunos publicados primero en medios de comunicación, con la descripción de los feminicidios en los límites del Estado de México y la ciudad capital, el 


\section{DISERTACIONES}

ESTUDIOS

Los desafíos del periodismo narrativo

ISSN: 1856-9536

Doi: https://doi.org/10.12804/revistas.urosario.edu.co/disertaciones/a.8474

Volumen 14, Número 1 / Enero-junio 2021

Versión PDF para imprimir desde

http://revistas.urosario.edu.co/index.php/disertaciones

tema se volvió más visible en la agenda periodística, sobre todo porque las cifras, como vimos, seguían incrementándose, y porque las autoridades parecían no tener capacidad de respuesta.

En marzo de 2020, parte de ese enojo social que generó el tema se tornó en un grito silencioso con una manifestación masiva el lunes 9 de marzo de rechazo a la violencia contra las mujeres, que tuvo réplicas en prácticamente todas las capitales del país.

Este periodismo narrativo cumple la función de "dar voz a los marginados de su sociedad" (Nadeau, 1999, p. 23), además entra en las categorías de denuncia, pruebas, testimonios, metáforas y seguimiento con el que se sustenta este texto.

\section{La estafa maestra}

El 5 de septiembre de 2017 (el formato de libro apareció un año después) salió a la luz una de las investigaciones que más ha llamado la atención en el periodismo mexicano de forma reciente, el título fue, además, atinado y contagioso: La estafa maestra, que jugaba con el trasfondo de la investigación que realizó un grupo de reporteros auspiciados por la asociación Mexicanos contra la Corrupción y el medio digital Animal Político.

Revisaron 73 convenios con 186 empresas investigadas, donde se rastrearon 7670 millones de pesos que fueron entregados en lo que se señalaba como contratos ilegales. El trabajo realizado en instituciones del gobierno de la república fue seguido de cerca por el equipo de periodistas, quienes al final señalaron la participación de 11 dependencias federales, 8 universidades y más de medio centenar de funcionarios.

Uno de sus pilares, a diferencia de los otros dos casos, es que este grupo efectuó más de 500 solicitudes de información y utilizó una base de datos con más de 13000 registros. Era un "trabajo original del periodista, realizado gracias a su iniciativa y no a los intereses de fuentes que filtran la información con objeto de conseguir determinados réditos" (Romero Domínguez \& García Orta, 2019, p. 28).

La investigación periodística generó que se profundizara en la indagatoria desde el gobierno en la época final de la administración del presidente Enrique Peña Nieto, y sobre todo al inicio de la administración del presidente Andrés Manuel López Obrador. El trabajo reporta que 3433 millones de pesos simplemente desaparecieron en empresas ilegales, otros mil millones en comisiones para las universidades y el resto se convirtió en servicios contratados a precios inflados (Roldán et al., 2018).

El proceso que duró seis meses incluyó visitas a los lugares donde se ubicaban físicamente las empresas que el gobierno había supuestamente contratado, pero en algunos sitios lo que hallaron no correspondía precisamente con las características de una empresa, sino más bien con lo que se conoce como empresas fantasmas, esto es, que dejan de existir después de cobrar por lo que las contrataron.

En la investigación se buscaron los trabajos llevados a cabo por las universidades involucradas, conocidos como entregables o testigos de las actividades que supuestamente estipulaban los contratos, pero los resultados no correspondían con la realidad.

El tema de la corrupción ya venía en ese momento creciendo en contra del gobierno del presidente Peña Nieto y esto vino a ejemplificar de una manera contundente lo que muchos pensaban o señalaban, pero hasta entonces no se tenían pruebas. 


\section{DISERTACIONES}

ESTUDIOS

Los desafios del periodismo narrativo

ISSN: 1856-9536

Doi: https://doi.org/10.12804/revistas.urosario.edu.co/disertaciones/a.8474

Volumen 14, Número 1 / Enero-junio 2021

Versión PDF para imprimir desde

http://revistas.urosario.edu.co/index.php/disertaciones

Un caso que reflejó una crisis de valores desde las instituciones mismas del gobierno. Y es que en México "la sanción legal tarda. O puede no llegar, como sucede en la mayoría de los casos, porque la impunidad es la marca de la casa" (Roldán et al., 2018, p. 16).

Buena parte del valor periodístico que sustenta este esfuerzo es que aparece cuando todavía se encuentra en funciones el gobierno denunciado (Bautista Farías, 2018), ese sentido de oportunidad genera reacciones positivas en la sociedad debido a otros escándalos de corrupción que se dieron en ese gobierno.

En materia de combate a la corrupción, el sexenio de Enrique Peña Nieto comenzó con muchas expecta-

tivas. Empero, a pesar de promesas y discursos, el sexenio 2012-2018 estuvo plagado de escándalos de corrupción -de hecho, algunos muy cercanos al presidente, su familia y a su grupo político, el "nuevo PRI"-. Pero, sobre todo, fue un sexenio en el que, a juzgar por los indicadores de percepción pública, la corrupción en la política y en la administración pública no sólo no menguó, sino que acaso se hizo más evidente (Nieto, 2020, p. 685).

Hay que subrayar la labor especial que realizaron los involucrados para presentar de forma atractiva el producto final de su investigación, se diseñaron piezas pensadas para un público que recurriría al universo de plataformas web para hacerse de la información; el esfuerzo estuvo dirigido por Salvador Camarena y Daniel Moreno, y la investigación por Miriam Castillo, Nayeli Roldán y Manuel Ureste.

Sobresalieron las infografías, las animaciones, el video, incluso se creó un cómic para tener un mejor vehículo donde se trasladara el lector para su comodidad. Una narrativa transmediática (López, 2016) que incluyó un trabajo de difusión en redes sociales y web muy intenso, que complementa lo mencionado por Toussaint y García Méndez al señalar que Animal Político "trabaja más sobre los géneros de opinión y artículos de fondo" (2017, p. 17).

Este trabajo recibió los premios Ortega y Gasset 2018 en la categoría mejor historia o investigación periodística, así como el Nacional de Periodismo 2017 en la categoría de reportaje.

Entra con las categorías de denuncia, pruebas, testimonios y seguimiento, sin embargo, no utiliza la metáfora o privilegia más las muchas cifras y datos que lo sostienen.

Es de resaltar que en lo que respecta al seguimiento a lo expuesto en su contenido, las investigaciones han continuado, incluso se encuentra en prisión Rosario Robles, quien ocupara la titularidad de la Secretaría de Desarrollo Social (2012-2015), así como la Secretaría de Desarrollo Territorial y Urbano (2015-2018), siendo una muestra de lo que muchos califican como actos de corrupción cometidos desde dentro de las instituciones del gobierno.

\section{El cártel de Sinaloa}

Diego Enrique Osorno en El cártel de Sinaloa, una historia de uso político del narco (2009) que conforma un mosaico de piezas necesarias para poner a la luz uno de los temas que marcaría el devenir del actuar del gobierno federal contra los grupos delictivos llamados carteles, dedicados sobre todo al tráfico de drogas o narcotráfico.

Reportero, entrevistador, cronista, tenía claro desde el inicio cuál era el objetivo de su trabajo: "Este reportaje intenta responder una pregunta central, más allá del conteo de ejecutados y las noticias estridentes sobre la detención de capos y más capos, y de lugartenientes y de operadores y demás. ¿Qué es el cártel de Sinaloa?" (Osorno, 2009, p. 50). 


\section{DISERTACIONES}

ESTUDIOS

Los desafios del periodismo narrativo

ISSN: 1856-9536

Doi: https://doi.org/10.12804/revistas.urosario.edu.co/disertaciones/a.8474

Volumen 14, Número 1 / Enero-junio 2021

Versión Pof para imprimir desde

http://revistas.urosario.edu.co/index.php/disertaciones

En el prólogo del libro, Froylán Enciso describe la labor del autor: "Es un libro urgente, porque representa una denuncia contra un presidente que gobierna con la sangre y contra la clase social que representa; es un libro que busca alternativas desde el conocimiento histórico y combate el silenciamiento de voces fundamentales en la discusión pública, sin dejarse intimidar por fundamentos morales" (Osorno, 2009, p. 16).

En sus páginas describe las consecuencias que trajeron las acciones emprendidas por el gobierno del presidente Felipe Calderón (2006-2012), y que lamentablemente tiempo después se comprobaron. Una mala estrategia para enfrentar uno de los males que más ha causado derramamiento de sangre en territorio mexicano. "Como resultado de la guerra contra el narcotráfico se incrementó el número de cárteles de las drogas en el período de Calderón" (Rosen \& Zepeda, 2015, p. 159).

Aunado a ello el hecho de que la violencia en México no solo afectó a quienes se dedicaban a ese tipo de actividades ilegales, sino que también impactó en la sociedad general, inmersa en la llamada guerra contra el narcotráfico (Rosen \& Zepeda, 2015). Incluso algunos estudios aseveran que en México el nivel de paz se ha deteriorado un 21,5\% desde 2015 (Instituto para la Economía y la Paz, 2019).

Diego Enrique Osorno utiliza elementos del periodismo narrativo, como la entrevista y el testimonio, va armando una crónica fluida y permanente, envía detalles al lector para que se ate capítulo a capítulo donde describe el vacío de poder que se incubó en las instituciones de gobierno durante años como consecuencia de las relaciones entre algún grupo de la clase gobernante y los grupos delincuenciales.

El trabajo ofrece detalles que solo quienes están o estuvieron dentro de estas organizaciones conocen, la labor de compilador de información y de narrador hacen que esta obra fuera punta de lanza para la literatura que sobre el narcotráfico se siguió produciendo y que hasta la fecha se puede ver (Mercado, 2016).

El mismo autor no soltó el tema del narcotráfico, siguió con el libro La guerra de Los Zetas (Osorno, 2012), donde se habla de otro de los grandes grupos delincuenciales que se han visto en años recientes en México.

El tema del narcotráfico ha seguido en México creciendo y se refleja en espacios de control, así como en flujo de dinero y, sobre todo, en el derramamiento de sangre, que no se ha detenido con el paso del tiempo con los 34582 en 2019 y 33743 en 2018 (SESNSP, 2020b).

Al igual que con los otros casos analizados, este también entra en las categorías de denuncia, pruebas, testimonios, y sí utiliza la metáfora en su contenido. En cuanto al seguimiento, por desgracia el tema de la violencia provocada por grupos delincuenciales en México ha venido en crecimiento.

La estrategia institucional y de comunicación de parte de la administración del presidente Felipe Calderón llamada Guerra contra el narco hizo que el tema se posicionara como central pese a que no fuera efectivo: "En la comunicación llevada a cabo por el gobierno, éste defiende férreamente la estrategia que se puso en marcha al comienzo del sexenio, es casi imposible que se acepten las fallas que han tenido, escudándose en el argumento de que ningún gobierno había tomado acciones en contra de esta problemática, que la estrategia es por el bien de todos los mexicanos y que abandonarla es una irresponsabilidad” (Reyes \& O'Quinn, 2013, p. 66).

Mientras que en la administración siguiente, la del presidente Enrique Peña Nieto, si bien se intentó disminuir el impacto mediático en cuanto al tema de la lucha por la seguridad, en los resultados no se notaba una mejoría: "A diferencia de los materiales de mercadotecnia diseñados para promocionar la acción del gobierno, que eran muy atractivos, el discurso carecía de las características que acompañan a las buenas historias, y por tanto de valor noticioso" (Meyenberg, 2019, p. 118). 


\section{DISERTACIONES}

ESTUDIOS

Los desafíos del periodismo narrativo

ISSN: 1856-9536

Doi: https://doi.org/10.12804/revistas.urosario.edu.co/disertaciones/a.8474

Volumen 14, Número 1 / Enero-junio 2021

Versión PDF para imprimir desde

http://revistas.urosario.edu.co/index.php/disertaciones

\section{Intelectual orgánico}

México tiene una tradición de periodismo narrativo que ubica a diversos personajes como precursores de lo que hoy vemos en diversos medios tradicionales, así como en librerías y en el mundo digital.

En el periodismo narrativo, hay conciencia de las relaciones entre periodismo y literatura, el uso de recursos que se intercambian y la aplicación de estrategias similares en la concepción de los textos (Puerta Molina, 2018).

El cronista en México, como se ha apuntado, reflejaba un momento en el desarrollo del país, y en sus textos también denunciaba posibles comportamientos, acciones o actitudes que la clase gobernante tomaba nota para hacer la parte que le tocaba. Además, una parte de estos intelectuales ayudaban en labores gubernamentales a generar ciertas directrices en el convite social, en ocasiones apoyando labores del mismo gobierno o señalando posibles conflictos.

Ante la complejidad de la relación entre los intelectuales y de su posición ante el Estado de la revolución institucional, este último conformó un sistema de privilegios para la intelectualidad, fundamentando su oferta en base a la disyuntiva de la promoción y permanencia en el medio -apoyada por el propio Estado mediante becas y cargos - o bien mantener su independencia con riesgo de ser condenados al olvido. La mayoría de los intelectuales optaron por la propia definición de su rol en esta sociedad de convivencia, señalando el quehacer intelectual sin confrontar su particular enfoque político (Palau, 2007, p. 84).

La crítica que se expresaba en sus crónicas, así como en sus otros espacios, ya que era hasta cierto punto normal que tuvieran participaciones en diferentes medios de comunicación, era considerada por la clase gobernante en turno y se generaban respuestas.

Hoy en día, con el periodismo narrativo que se impulsa a partir de la crisis de las instituciones de gobierno, los periodistas narrativos describen de muy buena manera, informan, investigan, analizan, pero, a diferencia de sus antecesores, no esperan un lugar en la esfera pública como personaje de renombre.

Los espacios ganados en los medios de comunicación son a pulso, y con el creciente impulso de plataformas digitales si bien han abierto la posibilidad para que lleguen a un mayor público, también es natural que más personajes participen en el debate, y la cantidad a veces excesiva hace que algunas voces se pierdan, razón quizá por la que los mismos periodistas narrativos prefieran enfocarse en su labor y dejar de lado el glamour que anteriormente otros sí ejercían (D’Lugo, 2002; Rodríguez, 1994).

El desgaste de las instituciones de gobierno que reflejan los trabajos aquí presentados tiene diversas causas, formas, personajes y consecuencias. El alejamiento del gobierno con su sociedad es una razón de peso, la ausencia de reflejos para adoptar prácticas como transparencia o gobierno abierto (Rivera, 2015), y buena parte de la opacidad que se reflejaba acrecentaba los enojos sociales, sumado a la falta de resultados y a una notoria diferencia económica entre las clases sociales. 


\section{DISERTACIONES}

ESTUDIOS

Los desafíos del periodismo narrativo

ISSN: 1856-9536

Doi: https://doi.org/10.12804/revistas.urosario.edu.co/disertaciones/a.8474

Volumen 14, Número 1 / Enero-junio 2021

Versión PDF para imprimir desde

http://revistas.urosario.edu.co/index.php/disertaciones

\section{Conclusiones}

Las instituciones en México con índices de calificación más bajos son las que tienen que ver con la clase política señalada por su abuso de autoridad, su ausencia de resultados y corrupción. Aunque también habría que decirlo, es más un vacío de poder y falta de estrategia donde la inseguridad y sus esquirlas detonaron parte del periodismo narrativo que ahora se observa, y que también refleja las consecuencias de esa crisis.

Los tres casos que se presentan aparecieron primero como piezas en medios impresos y/o digitales, y de allí luego tomaron la forma de libro, sobresale la difusión que han tenido y el reconocimiento público.

Cada uno de ellos generó que se pasara de la mención a la denuncia, del señalamiento a la acusación formal y legal, situación que los ha marcado como ejemplos para subsecuentes investigaciones, además de que se utilizan como referentes en el lenguaje periodístico.

Este periodismo narrativo que surge de la crisis cumple con todos los elementos técnicos. Conlleva la denuncia como bandera y ha logrado que también se entiendan mejor los fenómenos que exponen y, en esa medida, aspiren a tener resultados más deseables las mismas instituciones de gobierno.

Los tres casos enunciados también contienen los elementos de denuncia, pruebas, testimonios, seguimiento y metáforas (salvo uno de ellos), por lo que se pueden analizar como un conjunto de piezas perteneciente a un contexto mexicano caracterizado por el desgaste y bajas calificaciones de sus instituciones gubernamentales.

Sobresale el uso de minería de datos en una de las piezas, así como la comunicación transmediática, aspecto que sobre todo los medios digitales cada vez exploran más.

En todos los casos, el seguimiento que se dio después de las piezas publicadas ha conllevado respuestas como denuncias, procesos judiciales contra algunos de los personajes señalados, mayor entendimiento del fenómeno de los grupos delincuenciales, revisión en áreas donde se supone se imparte justicia, por mencionar los más visibles.

Luego del análisis vale la pena preguntarnos si esta crisis de las instituciones de gobierno en México seguirá dando material para este tipo de periodismo narrativo, o si bien al mejorar en su desempeño el gobierno, lo cual es deseable en todos los sentidos, el periodismo narrativo virará hacia otros intereses.

\section{Referencias}

1. Amado, A. (2016). Del newsroom al cloudsroom. El periodista y los productores de información. En Desafíos del periodismo en la sociedad del conocimiento. Discusiones a partir del Tercer Seminario Brasil-Argentina de Pesquisa em Jornalismo. Editorial UnRN.

2. Basañez, M. (1990). El pulso de los sexenios. 20 años de crisis en México. Siglo xxı Editores.

3. Bautista Farías, J. (2018). La corrupción en México: cambios y alternativas. Análisis Plural.

4. Cairati, E. (2013). Periodismo narrativo peruano como territorio de la subalternidad. Anales de Literatura Hispanoamericana, 42, 41-54.

5. Cantavella, J., \& Serrano, J. (Coords.). (2004). Redacción para periodistas: informar e interpretar. Ariel.

6. Carrión, L. (2017). La fosa de agua. Debate. 


\section{DISERTACIONES}

ESTUDIOS

Los desafios del periodismo narrativo

ISSN: $1856-9536$

Doi: https://doi.org/10.12804/revistas.urosario.edu.co/disertaciones/a.8474

Volumen 14, Número 1 / Enero-junio 2021

Versión PDF para imprimir desde

http://revistas.urosario.edu.co/index.php/disertaciones

7. Consulta Mitofsky. (2015). México: confianza en instituciones 2015.

8. Consulta Mitofsky. (2016). México: confianza en instituciones 2016.

9. Consulta Mitofsky. (2017). México: confianza en instituciones 2017.

10. Consulta Mitofsky. (2018). México: confianza en instituciones 2018.

11. Consulta Mitofsky. (2019). México: confianza en instituciones 2019.

12. D’Lugo, M. (2002). Carlos Monsiváis: escritos sobre el cine y el imaginario cinematográfico. Revista Iberoamericana, (199), 283-301.

13. Darrigrandi, C. (2013). Crónica latinoamericana: algunos apuntes sobre su estudio. Cuadernos de Literatura, XVII(34), 122-143.

14. Deutsch, K. (1969). Los nervios del gobierno. Modelos de comunicación y control político. Paidós.

15. García Jiménez, A., Tur-Viñes, V., \& Pastor Ruiz, Y. (2018). Consumo mediático de adolescentes y jóvenes. Noticias, contenidos audiovisuales y medición de audiencias. Icono 14, 16(1), 22-46. https://doi.org/10.7195/ ri14.v16i1.1101

16. Giddens, A. (1999). Un mundo desbocado. Los efectos de la globalización en nuestras vidas. Taurus.

17. González, L. (2019). Clientelismo y democracia: descifrando una (difícil) relación. En Clientelismo, patronazgo y corrupción en Colombia y México. Universidad del Norte.

18. Hartsock, J. C. (2000). A history of American literary journalism: the emergence of a modern narrative form. University of Massachusetts Press.

19. Instituto para la Economía y la Paz. (2019). Índice de Paz México. Identificar y medir los factores que impulsan la paz. Institute for Economics \& Peace.

20. Kapuscinski, R. (2002). Los cínicos no sirven para este oficio. Anagrama.

21. López, A. (2016). El periodismo que contará el futuro. Chasqui. Revista Latinoamericana de Comunicación, (131), 239-256.

22. López, F. (2010). Periodismo literario: entre la literatura constitutiva y la condicional. Ámbitos, (19), 97-116. http://www.redalyc.org/articulo.oa?id=16820577006

23. Mercado, A. (2016). ¿Es posible explicar el narcotráfico desde el periodismo narrativo? (Ensayo para obtener título universitario, UAEM).

24. Meyenberg, Y. (2019). La comunicación en la presidencia de Enrique Peña Nieto. En Estrategias de comunicación presidencial en México (1994-2018). unam.

25. Monsiváis, C. (1980). A ustedes les consta. Editorial Era.

26. Nacif, B. (2007). Para entender las instituciones políticas del México democrático. CIDE.

27. Nadeau, E. (1999). Entre la ficción y el periodismo: cambio social y la crónica mexicana contemporánea. Mester, XXVIII.

28. Nieto, F. (2020). El legado del "sexenio de la corrupción": los retos del Sistema Nacional Anticorrupción. Foro Internacional, 60(2).

29. Novak, A. (2018). Designing a renaissance for digital news media. Media and Communication, 6(4), 115-118. https://doi.org/10.17645/mac.v6i4.1769

30. Osorno, D. (2009). El cártel de Sinaloa. México: Grijalbo.

31. Osorno, D. (2012). La guerra de Los Zetas. México: Grijalbo. 


\section{DISERTACIONES}

ESTUDIOS

Los desafios del periodismo narrativo

ISSN: $1856-9536$

Doi: https://doi.org/10.12804/revistas.urosario.edu.co/disertaciones/a.8474

Volumen 14, Número 1 / Enero-junio 2021

Versión PDF para imprimir desde

http://revistas.urosario.edu.co/index.php/disertaciones

32. Palau, P. (2007). Intelectuales y poder en México. América Latina Hoy, 77-85.

33. Pastor, E. (2017). El periodismo narrativo de Diego Enrique Osorno y su compromiso con la realidad mexicana a través de sus crónicas: El cártel de Sinaloa, La guerra de Los Zetas y La ira de México (Trabajo de fin de grado, Universidad de Sevilla).

34. Puerta Molina, A. (2018). La crónica, una tradición periodística y literaria latinoamericana. Historia y Comunicación Social, 213-229.

35. Puerta Molina, A. (2019). Crónica latinoamericana: las revistas, hábitat natural del periodismo bien hecho. Revista Chilena de Literatura, (99), 317-340. https://dx.doi.org/10.4067/S0718-22952019000100317

36. Reyes, R., \& O’Quinn, J. (2013). La comunicación gubernamental de la guerra contra el narcotráfico en México. Espacios Públicos, 16, 55-75.

37. Rivera, B. (2015). Crisis institucional y gobierno abierto. Nexos. https://redaccion.nexos.com.mx/?p=6871

38. Rodríguez, X. (1994). El poder como espejo de los intelectuales. Revista Mexicana de Ciencias Políticas y Sociales, 39(158).

39. Roldán, N., Castillo, M., \& Ureste, M. (2018). La estafa maestra. Graduados en desaparecer el dinero público. Temas de Hoy.

40. Romero Domínguez, L., \& García Orta, M. (2019). Cómo destapar otro Panama Papers. Nuevos retos para el periodismo de investigación. voc.

41. Rosen, J., \& Zepeda, R. (2015). La guerra contra el narcotráfico en México: una guerra perdida. Revista Reflexiones, 153-168.

42. Sabaté Gauxachs, A., Micó Sanz, J. L., \& Díez Bosch, M. (2019). El nuevo nuevo periodismo digital como activismo. Análisis de Jot Down, Gatopardo y The New Yorker. Communication \& Society, 32(4), 173-191.

43. Sandoval, W. (2020). ¿Cómo determinar y clasificar, para luego contribuir a superar las prácticas de corrupción en el órgano ejecutivo salvadoreño? (Trabajo final de graduación para optar al grado de Magíster en Dirección Pública, Pontificia Universidad Católica de Valparaíso).

44. Secretariado Ejecutivo del Sistema Nacional de Seguridad Pública. (2020a). Información sobre violencia contra las mujeres. Centro Nacional de Información del SESNSP (corte al 31 de marzo de 2020). https://drive. google.com/file/d/1jew7rwBA09ub6dgROme4uFaOwYaF6hHv/edit

45. Secretariado Ejecutivo del Sistema Nacional de Seguridad Pública. (2020b). Informe de incidencia delictiva fuero común. Centro Nacional de Información del SESNSP (corte al 31 de diciembre de 2019). https:// drive.google.com/file/d/1g2HCuXR8vODs_UsnUSwWyE_Kc8lm5yme/view

46. Sims, N. (1996). Los periodistas literarios o el arte del reportaje personal. El Áncora Editores.

47. Toussaint Alcaraz, F., \& García Méndez, C. A. (2017). Riesgo y desastres en el periodismo por internet: el caso de México. Anuario Electrónico de Estudios en Comunicación Social Disertaciones, 10(2), 10-19.

48. Valverde, J., \& Argüelles, J. (1992). El fin de la nostalgia. Editorial Nueva Imagen.

49. Vargas, X. (2007). ¿Cómo hacer investigación cualitativa? Etxeta.

50. Villarreal, H. (2012). El periodismo narrativo. Entrevista con Leila Guerriero. Revista Replicante. https:// revistareplicante.com/el-periodista-narrativo/ 